Article

\title{
Why Are Scientific Experts Perceived as Trustworthy? Emotional Assessment within TV and YouTube Videos
}

\author{
Anne Reif *, Tim Kneisel, Markus Schäfer and Monika Taddicken \\ Department of Communication and Media Sciences, Technische Universität Braunschweig, 38106 Braunschweig, Germany; \\ E-Mails: a.reif@tu-braunschweig.de (A.R.),t.kneisel@tu-braunschweig.de (T.K.), m.schaefer@tu-braunschweig.de (M.S.), \\ m.taddicken@tu-braunschweig.de (M.T.)
}

* Corresponding author

Submitted: 2 October 2019 | Accepted: 8 December 2019 | Published: 18 March 2020

\begin{abstract}
Due to the rise of the Internet, the effects of different science communication formats in which experts appear cannot be neglected in communication research. Through their emotional and more comprehensible communication 'sciencetubers' - who frequently differ from the stereotypical image of scientists as white, old men-may have a considerable effect on the public's perceived trustworthiness of scientists as well as their trust in science. Thus, this study aims to extend trust and trustworthiness research to consider the role of emotion in science communication in the context of emerging online video content. Therefore, perceived trustworthiness was examined in an experimental online survey of 155 people aged 18-80. We considered different potential influencing variables for trustworthiness (expertise, integrity, benevolence) and used six different video stimuli about physics featuring scientific experts. The video stimuli varied according to format (TV interviews vs. YouTube videos), gender (male vs. female), and age of the experts depicted (old vs. young). The results suggest that: (1) Scientific experts appearing in TV interviews are perceived as more competent but not higher in integrity or benevolence than sciencetubers-while scientists interviewed on TV are regarded as typical scientists, sciencetubers stand out for their highly professional communication abilities (being entertaining and comprehensible); (2) these emotional assessments of scientists are important predictors of perceived trustworthiness; and (3) significantly mediate the effect of the stimulus (TV interview vs. YouTube video) on all dimensions of perceived trustworthiness of scientific experts.
\end{abstract}

\section{Keywords}

entertainment; public trust; science communication; science video; stereotype; television; trustworthiness; YouTube

\section{Issue}

This article is part of the issue "Emotions and Emotional Appeals in Science Communication" edited by Monika Taddicken (Technische Universität Braunschweig, Germany) and Anne Reif (Technische Universität Braunschweig, Germany).

(C) 2020 by the authors; licensee Cogitatio (Lisbon, Portugal). This article is licensed under a Creative Commons Attribution 4.0 International License (CC BY).

\section{Introduction}

Scientific topics are often very complex and difficult to grasp, particularly for non-experts. However, scientific findings form the basis for many everyday life decisions which is why the public require a certain degree of trust in science and the work of scientists.

This is especially true nowadays, given that the public now has the ability to immediately access information at any time from a wide variety of sources. The
Internet has a great deal to offer non-experts who wish to inform themselves on a topic. New online platforms allow scientists to easily communicate their results to the public and other scientists. The Internet thereby helps to make science more accessible and enables the public to engage with science or even publish their own content about science. At the same time, correctly evaluating an alleged expert and their trustworthiness becomes more challenging (Hendriks, Kienhues, \& Bromme, 2015), as "[d]ifferent levels of expertise, qual- 
ity, balanced outcome, and scientific evidence can be found online" (Taddicken \& Reif, 2016, p. 318).

Furthermore, science content on social media has the potential to portray the true diversity of scientists more realistically and thereby has the potential to break down the existing stereotype of scientists as being competent but cold (Jarreau et al., 2019), as well as to increase trust in scientists and science in general. Increasingly, formats such as science videos uploaded to online platforms such as YouTube can help present scientists as 'normal' people by not only disseminating facts but also emotions. In this article, we argue that the perceived trustworthiness of scientific experts is merely based on a 'gut feeling' and emotional processes. By emotional and more comprehensible communication 'sciencetubers' who often also differ from the stereotypical image of scientists as white, old men-may have a considerable effect on the public's perception of scientists as trustworthy and thereby on the public's trust in science.

By considering different theoretical and methodological frameworks of trust, trustworthiness or credibility, we use the epistemic trustworthiness inventory by Hendriks et al. (2015) as a starting point which was specifically developed for evaluating scientific experts in online environments. We present results from an experimental online survey ( $n=155$ ) comparing perceptions of scientific experts appearing in classical TV interview settings with sciencetubers. We address the underlying question of what the predictors of perceived trustworthiness are and which role emotional assessment plays.

\section{Trust in and Trustworthiness of Scientists as Research Issue}

\subsection{Science Media Use: Building Trust through Emotional Responses}

Moving image content is the most frequently used source of information about science in Germany. Whereas TV is the overall most frequently used source, the Internet is in second place including online TV libraries and video platforms such as YouTube (Wissenschaft im Dialog, 2018). While science magazines and documentaries on German television are mostly produced by journalists or professional freelancers, scientists often 'only' appear as interview guests (Janecek, 2008). These established formats are supplemented by online video platforms, with new science video formats and new actors on stage. A recent study found that usergenerated science videos are more popular than professionally generated ones (Welbourne \& Grant, 2016). However, nowadays it has become hard to differentiate between user and professionally generated content as, for instance, so-called 'influencers' or 'sciencetubers' are often professional communicators as well.

Social media allows for direct communication between scientific experts and the lay audience and has been postulated as a way to increase the perception of scientists' trustworthiness (Jarreau et al., 2019) as well as trust in science (Lakomý, Hlavová, \& Machackova, 2019). Polls indicate that people have more trust in information produced directly by scientists than scientific information mediated by the journalistic mass media (European Commission, 2013). However, surveys asking for the trustworthiness of social versus traditional mass media find that most people in Germany do not evaluate social media as trustworthy (Kaczinski, Hennig-Thurau, \& Sattler, 2019). Often, social media is accused of being connected to disinformation, so-called 'fake news' (Spohr, 2017). Those surveys do, however, neglect the fact that social media are not to be seen as 'the opposite' of traditional journalistic media; journalistic content is also widely distributed in social media and integrated into social media content. Thus, it is important to thoroughly distinguish between various dimensions and aspects when researching different video content.

One key distinguishing factor may be the emotions that sciencetubers arouse. For media reception in general, positive feelings of enjoyment and pleasure are at the core of entertainment experiences (Schweiger, 2013). Many science communicators hope to better reach the public through an 'edutainment' approach that focuses on the emotional experience of audiences (Gerber, 2012) and is easy to access (Friesen, van Stan, \& Elleuche, 2018). Yet, while many scientists call for a more entertaining style of science communication (Friesen et al., 2018; Gigante, 2018), the effects of edutainment-focused science communication have hardly been studied outside of the context of the educational system. The literature here indicates that entertainment-focused methods of teaching (such as gamification) increase student engagement and interest (Rabah, Cassidy, \& Beauchemin, 2018). New online formats such as YouTube videos and TED talks often focus on entertainment (Sugimoto et al., 2013). In addition, one could also assume a connection to trustworthiness, for example, because of the stronger personal connection between the communicator and the audience.

According to qualitative group interviews among nonscientists, good and trustworthy scientists stand out for their ability to explain highly complex scientific issues in a way that even non-experts can understand (Reif, in press). Therefore, comprehensibility can be expected to positively affect the perceived trustworthiness of scientific experts. Compared to scientists in traditional TV formats, sciencetubers are expected to explain scientific content in a more comprehensible way. They are often experienced and professional science communicators. By analysing direct user feedback, they are able to evaluate which ways of communication and video styles viewers appreciate or even expect.

\subsection{Trust in Stereotypical Scientists}

Previous studies have empirically proven that children (e.g., Buldu, 2006; Finson, 2002; Türkmen, 2008) and 
adults (Carli, Alawa, Lee, Zhao, \& Kim, 2016; Reif, in press) have stereotypical beliefs about scientists as being older, white men, and consider Albert Einstein and Stephen Hawking as typical and at the same time trustworthy scientists. Scientists and researchers are "[a]mbivalently perceived high-competence but low-warmth, 'envied' professions" in the scheme of the stereotype content model (Fiske \& Dupree, 2014, p. 13593)-traits that stereotypically are also attributed to men. Stereotypical beliefs about women, by contrast, still picture them as low in competence but high in warmth (Fiske, Cuddy, Glick, \& Xu, 2002). The media also reinforces these stereotypical views (or may have even caused them, according to cultivation theory). Until today, female science experts are underrepresented in the media. Male scientists are quoted as experts more frequently while women's voices are often only heard as everyday people (Kitzinger, Chimba, Williams, Haran, \& Boyce, 2016; Röben, 2013). In German television, more than twothirds of experts who appear are male (Prommer \& Linke, 2017). By contrast, social media may help to break down existing stereotypes about scientists by presenting them more realistically as a diverse group of people (Jarreau et al., 2019). However, only less than ten percent of the most popular science, technology, engineering, and mathematics (STEM) related YouTube channels are hosted by women (Amarasekara \& Grant, 2019).

\subsection{Defining and Examining Trust and Trustworthiness}

In order to embed the present study in the context of previous research, we will clarify how we define and distinguish trust and trustworthiness in the following section. Most studies so far have focused either on trust or trustworthiness/credibility, and often use the different terms interchangeably (Hasell, Tallapragada, \& Brossard, 2019).

Psychological research often focuses on how trust is gained and lost. However, these processes are still far from being fully understood (Simpson, 2007). The term and its derivations and negations can be described by a variety of concepts that include personal and situational conditions (Dernbach \& Meyer, 2005). Among others, trust is defined as the willingness to make oneself vulnerable to the actions of another party (Mayer, Davis, \& Schoorman, 1995), in this case, to rely on the statements of experts. This vulnerability demonstrates that trust is always based on emotion rather than logical evaluation (Aljazzaf, Perry, \& Capretz, 2010). Furthermore, previous research distinguishes between trust in people and trust in systems (Giddens, 1991; Hendriks et al., 2015) as well as between generalised and specific trust (Grünberg, 2014). General trust in a system (here: science) or a group of people (in this case: scientists) is developed based on cumulative experiences with specific people. In these specific situations and communicative contexts, the credibility of scientific information (Hasell et al., 2019) and trustworthiness of a specific individual are evaluated.
Trustworthiness can be defined as a feeling that a person can lead others to trust that person, a group of people, an organisation or even a system (Grünberg, 2014). Trust in turn influences evaluations of trustworthiness of specific individuals (here: other scientists; Aljazzaf et al., 2010) in a specific context. When evaluating a person who belongs to a group of people such as scientists, existing beliefs about this group are used to compare the person's appearance, character, and behaviour. Thus, while trust is a procedural variable that can change over time, trustworthiness is situational. Although both variables can logically be argued to be connected, the nature of this link is difficult to examine empirically.

Several researchers examine either general beliefs towards different groups of people (e.g., Fiske et al., 2002; Hovland, Janis, \& Kelley, 1953) or scientists in particular (e.g., Fiske \& Dupree, 2014) and thereby focus on trust according to the definition used here. Others apply experimental designs and stimulus material to examine how scientists' (e.g., Gheorghiu, 2017) and scientific experts' (e.g., Hendriks et al., 2015) trustworthiness is evaluated. Different theoretical constructs and dimensions, as well as the measures developed, are in many ways very similar. At the same time, constructs and measures differ regarding labelling and allocation of items.

Most commonly, constructs comprise either two or three dimensions. In the two-dimensional construct of so-called 'source credibility,' groups of people are always perceived on their competence/expertise (referred to as confidence by Earle \& Siegrist, 2006) as well as their warmth/trust/trustworthiness (e.g., Fiske et al., 2002; referred to as social trust by Earle \& Siegrist, 2006). Competence denotes "the knowledge and ability to be accurate" (Fiske \& Dupree, 2014, p. 13593). Warmth denotes the perceptions of people's intentions. As stated above, according to this scheme scientists and researchers are stereotypically believed to be high in competence and low in warmth (Fiske \& Dupree, 2014). While the dimension of competence/expertise seems uncontested by both, the two- as well as three-dimensional constructs, there are diverse approaches about how the warmth dimension may actually comprise two distinct dimensions. For example, Gheorghiu (2017) distinguishes between how likeable (sociability) and how trustworthy and honest (morality) a person is perceived by others. By contrast, McCroskey and Teven (2009) consider goodwill (the level at which people are believed to care about others) and also measure honesty and morality as trustworthiness. More specifically for the perceived trustworthiness of scientific experts in online contexts, Hendriks et al. (2015) differentiate between honesty regarding scientists' work (integrity) and scientists' good intentions and moral behaviours (benevolence).

\section{Aims of Research and Hypotheses}

The first aim of this research is to examine whether there are differences in how diverse scientific experts 
(male vs. female, old vs. young) appearing in different video formats (TV interviews vs. YouTube videos) are perceived. Following the METI-scale developed specifically for the perceived trustworthiness of scientific experts in online contexts, we measure perceived trustworthiness (expertise, integrity, benevolence) and distinguish it from emotional assessment of scientific experts. Based on the state of research, we sum up three different types of emotional assessment: a) Feeling entertained by a scientific expert is understood as affective assessment. Cognitive evaluations of scientific experts appearing in science videos include b) how comprehensible experts communicate science information and whether they are perceived as c) being typical scientists.

A vast body of literature has examined the stereotypical perceptions of scientists. Therefore, it can be assumed that male scientific experts are perceived as more competent but possessing less integrity and benevolence than female scientific experts. Furthermore, older scientists are assumed to be evaluated as more trustworthy than younger experts. Contrary, regarding potential effects of different video formats on trustworthiness, no unambiguous direct assumption can be made. Although it may seem plausible that sciencetubers are evaluated as more honest and benevolent, no clear effect is expected for expertise (Jarreau et al., 2019). Thus, we ask the first research question:

RQ1: Do scientific experts differ in their perceived trustworthiness (expertise, integrity, benevolence) when appearing in TV interviews compared to sciencetubers?

Although in light of the state of research no specific assumptions can be formulated for gender and age-related effects on the emotional assessment of scientific experts, we predict the following directional effects by video format:

H1a: Sciencetubers are perceived as more entertaining than scientific experts appearing in classical TV interviews.

H1b: Sciencetubers are perceived as communicating scientific information more comprehensibly than scientific experts appearing in classical TV interviews.

H1c: Sciencetubers are perceived as being less typical scientists than scientific experts appearing in classical TV interviews.

The second aim of this research is to identify the predictors of perceived trustworthiness in a regression model. We especially focus on the question:

RQ2: What role do different video formats as well as emotional assessments of scientific experts play?
We also include the gender and age of scientific experts as stimulus variables in our model. While we cannot predict the effect of scientific experts' varying abilities to entertain (affective assessment), we hypothesise the following for the cognitive assessment based on the literature review:

H2a: The assessment of scientific experts' ability to communicate comprehensibly positively predicts perceived trustworthiness.

$\mathrm{H} 2 \mathrm{~b}$ : The evaluation of scientific experts being typical scientists positively predicts perceived trustworthiness.

Based on the assumption that general trust in scientists and perceived trustworthiness of specific scientific experts are positively linked but different constructs, we test $\mathrm{H} 3$ in order to explore the size of potential effects:

H3: General trust in scientists is a positive predictor for perceived trustworthiness.

In addition to the potential predictors of perceived trustworthiness mentioned above, we also test the effects of viewers' attributes. Past research has shown that men report higher trust in science than women (Huber, Barnidge, Gil de Zúñiga, \& Liu, 2019; von Roten, 2016). For Germany, it has been shown that $59 \%$ of men and $48 \%$ of women have trust in science, with women being more likely to be undecided or to report distrust (Wissenschaft im Dialog, 2018). However, this gender effect could also indicate that women do not feel represented by science. As the media still often strongly reflects the stereotypical images of scientists. Thus, women may perceive science to be mainly male-dominated and therefore find it more difficult to have trust in science. The Wissenschaftsbarometer in Germany further reveals that older people have a lower level of trust in science (Wissenschaft im Dialog, 2018). This may indicate a possible decline in trust with age. But more likely, this is a reflection on an effect triggered by educational attainment. Higher knowledge about science was previously found to predict higher appreciation of (Lakomý et al., 2019) and increased trust in science (Wissenschaft im Dialog, 2018). These results may indicate that a higher degree of contact with science leads to a higher trust in science. We expect similar effects for the perceived trustworthiness of scientific experts and will therefore also test how viewers' attributes predict the three dimensions.

The final aim of the research is to test, by conducting parallel mediation analyses, the following research question:

RQ3: How do emotional assessments mediate the perceived trustworthiness of scientific experts appearing 
in different video content (TV interviews vs. YouTube videos)?

While the sciencetubers' higher ability to explain scientific content in a more entertaining and comprehensible way may mediate perceived trustworthiness, for scientific experts in classical TV interviews the stronger perceptions of them as being typical scientists may positively mediate perceived trustworthiness.

\section{Methods}

\subsection{Measures}

We used the METI-scale developed by Hendriks et al. (2015) as the primary tool for this online survey with experimental design. As the initial scale was only applied to the trustworthiness of scientists in blog articles/text descriptions, we tested the scale reliability using video stimuli in comparison to blog texts in a first pre-test $(n=82$ ) in summer 2018. Seven-point semantic differentials from negative to positive were applied. Expertise was measured by six items: incompetent/ competent; unintelligent/intelligent; poorly educated/ well-educated; unprofessional/professional; inexperienced/experienced; and unqualified/qualified. Four items were used to assess integrity (insincere/sincere, dishonest/honest, unjust/just, unfair/fair) as well as benevolence (immoral/moral, unethical/ethical, irresponsible/responsible, inconsiderate/considerate). Results revealed even higher internal consistencies for the dimensions when scientific experts in videos are evaluated compared to blog texts $(\alpha=.92-.96)$. In addition to the dependent variable of perceived trustworthiness, we measured variables regarding the affective (boring/entertaining) and cognitive assessment of scientists (incomprehensible/comprehensible, atypical/typical) as single items on seven-point semantic differential scales. Furthermore, respondents' interest in science ("no interest" to "high interest"), general trust in scientists ("very low" to "very high"), as well as science TV use and online video use about science ("rarely or never" to "daily") were assessed as single items on a five-point scale.

\subsection{Stimuli}

We decided to use real stimulus material to simulate realistic media exposure. In order to minimise effects outside the scope of investigation in this study, stimuli were selected to be about similar scientific topics and with the experts speaking in similar settings presenting not own but summarising the field's general scientific results. In total, six one-minute long excerpts of videos (TV interviews and YouTube videos) on different topics in physics were used as stimuli (Table 1). Physics was chosen because of its distance to the science-policyinterface, meaning that content is seen as comparably uncontroversial. The four stimuli were television inter- views with scientists talking about their own research (two males, two females). The experts' names, academic titles, and affiliations were not presented in the video clips. We chose videos from the TV series "alpha-Forum" with classic interview settings (host and scientific expert sitting opposite each other). The studio is dark and focuses on the host and scientist who both appear in formal clothing. The scientist answers questions about their research field, addressing the host rather than the viewer and uses technical terms. The text does not seem scripted. Furthermore, two science videos that were produced for YouTube were used in which a young, casually clothed expert (male/female) comprehensibly explains a topic in a studio setting with professional quality production. Sciencetubers who, for example, explain a topic in an outside setting or a private office were disregarded. Both sciencetubers have chosen to face the camera and use a scripted text.

\subsection{Sampling and Procedure}

Participants were recruited through two channels. Firstly, a short description of and the link to the study was emailed to the university department's pool of study participants. Secondly, a similar text was posted to different online forums and Facebook groups. In order to reach both users who are actively interested in science and those who are not, discussion communities with a focus on science and fan communities of entertainmentfocused YouTube channels were selected. In the text, the study was described as investigating the formation of opinions on scientists without stating which attributes were examined.

Respondents completed a standardised online survey in which they were first asked to indicate their interest in science, trust in scientists in general, and frequency of science TV use and online video use about scientific topics (Figure 1). Next, each participant was presented with a randomly assigned video stimulus. After watching the video, they were asked to evaluate the person shown (referred to as "expert") regarding their trustworthiness and emotional assessment. The items were not randomised. Following this, they were shown and asked to rate a second video stimulus, which was also randomly chosen but with the restriction of being of the opposite gender to the first one, meaning that each participant rated a male and a female expert. Concluding the survey, the demographic data age and education were captured.

After data collection, we included video type (TV interview vs. YouTube video), gender (male vs. female expert) and age (old vs. young expert) as dummy variables to the data set. Six participants who stated that they already knew the expert in stimulus 6 were removed. For data analysis, analyses of variance (RQ1, $\mathrm{H} 1 \mathrm{a}-\mathrm{c}$ ), linear regressions (RQ2, $\mathrm{H} 2 \mathrm{a}-\mathrm{b}, \mathrm{H} 3$ ), and parallel mediation analyses using Haye's PROCESS macro (version 3.0, model 4, RQ3) were calculated with 10.000 bootstrap samples. 
Table 1. Short description of video stimuli.

\begin{tabular}{llll}
\hline TV interview stimuli & \multicolumn{2}{l}{ YouTube videos stimuli } \\
\hline Stimulus 1 & & Stimulus 5 & \\
Topic: & Astrophysics: Formation of celestial bodies & Topic: & General physics: Subject matter light \\
Expert: & Male expert, 50 years of age & Expert: & Male expert, 34 years of age \\
TV series: & alpha-Forum & Channel: & musstewissen Physik \\
Video title: & Josef Martin Gaßner, Mathematiker und & Video title: & Lichtquellen I Lichtausbreitung I Optik I \\
& theoretischer Physiker (Josef Martin Gaßner, & & musstewissen Physik (Light sources I \\
& mathematician and theoretical physicist) & & Propagation of light I optics I \\
URL: & https://www.youtube.com/watch? & & musstewissen Physik) \\
& v=9OoHZuu_kwA & URL: & https://www.youtube.com/watch? \\
& & & v=llaoa5LHsgA
\end{tabular}

\section{Stimulus 2}

Topic:

Expert:

TV series:

Video title:

URL:

$$
\begin{aligned}
& \text { Astrophysics: Movement of bodies in space } \\
& \text { Male expert, } 80 \text { years of age } \\
& \text { alpha-Forum } \\
& \text { Eine Folge Alpha Forum-Im Interview mit } \\
& \text { Rudolf Kippenhahn (Astrophysiker \& Autor) } \\
& \text { (2006) (One episode of Alpha Forum- } \\
& \text { Interview with Rudolf Kippenhahn } \\
& \text { [astrophysicist and author] [2006]) } \\
& \text { https://www.youtube.com/watch? } \\
& \text { v=uamiDEpec78\&t=8s }
\end{aligned}
$$

\section{Stimulus 3}

Topic:

Expert:

Theoretical physics: Effect of magnetic fields

Female expert, 61 years of age

TV series:

$$
\text { alpha-Forum }
$$

Video title: Gisela Anton, Lehrstuhl für Experimentalphysik Universität Erlangen-Nürnberg (Gisela Anton, Chair in experimental physics University Erlangen-Nürnberg)

URL: $\quad$ https://www.youtube.com/watch?v=rTla6fZuhPI

\section{Stimulus 4}

Topic: Theoretical physics: Cycle of matter

Expert: $\quad$ Female expert, 36 years of age

TV series: alpha-Forum

Video title: Sibylle Anderl, Astrophysikerin und

Wissenschaftsjournalistin-ARD-alpha

(Sibylle Anderl, astrophysicist and science journalist-ARD-alpha)

URL: https://www.youtube.com/watch?

\section{Stimulus 6}

Topic: General physics with aspects of Expert: $\quad$ Female expert, 31 years of age Channel: maiLab

Video title: Solarautos (Solar-powered cars) URL: $\quad$ https://www.youtube.com/watch? $\mathrm{v}=\mathrm{kmNRhO}-\_7 \mathrm{w} 8$ $v=q V T 6 X J u v-G U \& t=7 s$ 


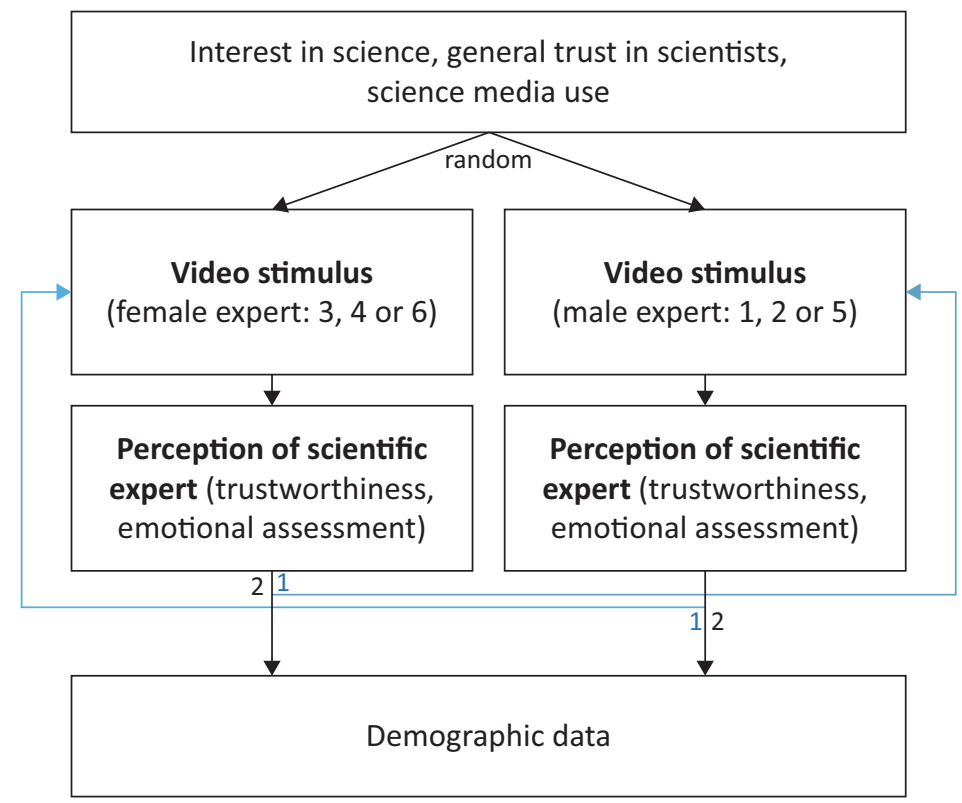

Figure 1. Experimental design of the study.

\section{Results}

The final sample consisted of 155 people aged between 18 and 80 , with $48 \%$ of participants aged between 20 and 29. More males than females completed the questionnaire and most people in the sample are highly educated (Table 2). Further, the respondents are rather interested in science $(M=4.04, S D=.88)$, trust in scientists to a good degree $(M=3.86, S D=.69)$. They use online videos about scientific topics more often $(M=3.08, S D=1.38)$ than science TV $(M=2.24, S D=1.31)$.

In total, and as with previous research (Fiske \& Dupree, 2014), respondents rated the scientists' exper- tise higher than their integrity and benevolence (Table 3). However, these findings do not support the assumption of there being an ambivalent stereotype of scientists as the experts, in fact, were perceived as possessing rather high degrees of integrity and benevolence. Regarding zero-order correlations, perceived expertise has a strong positive correlation with integrity and benevolence. Integrity and benevolence are highly correlated. An exploratory factor analysis also provides a possible hint towards only two dimensions: expertise and one other factor that combines integrity and benevolence (similar to e.g., Fiske et al., 2002; Hovland et al., 1953).

Table 2. Socio-demographic data of participants.

\begin{tabular}{lr}
\hline & $\%$ \\
\hline Gender & 61 \\
Male & 39 \\
Female & \\
Age & 2 \\
$14-19$ & 48 \\
$20-29$ & 11 \\
$30-39$ & 10 \\
$40-49$ & 13 \\
$50-59$ & 16 \\
$60+$ & \\
Education & 2 \\
Graduation from Secondary Education (Hauptschule) & 9 \\
Graduation from Secondary Education (Realschule) & 36 \\
Higher Secondary Education (Abitur) & 46 \\
University Degree & 6 \\
Doctoral Degree &
\end{tabular}

Note: $n=155$. 
Table 3. Descriptive statistics and Pearson correlations for dimensions of trustworthiness.

\begin{tabular}{lccc}
\hline & $M(S D)$ & Expertise & Integrity \\
\hline Expertise $(\alpha=.92)$ & $5.91(.98)$ & & $.48 * * *$ \\
Integrity $(\alpha=.87)$ & $5.47(1.02)$ & $.37^{* * *}$ & $.80^{* * *}$ \\
Benevolence $(\alpha=.92)$ & $5.10(1.09)$ & & \\
\hline
\end{tabular}

Notes: $n=302 ;{ }^{* *} p \leq .001$ (one-tailed); $M=$ mean, $S D=$ standard deviation.

\subsection{Impacts of Stimulus Exposure}

In a comparison of means of the six different video stimuli (Table 4), the experts depicted in stimulus 1 and 3 (TV interviews, older experts) received the highest rating of perceived expertise, while the younger sciencetuber in stimulus 5 received the lowest mean (RQ1). In addition to the mean differences between all six stimuli, we conducted analyses of variance for all three stimuli dummy variables as independent group variables and each dependent variable. These additional analyses indicated significant group differences regarding perceived expertise between the TV interview stimuli $(M=6.02$, $S D=.92)$ and YouTube stimuli $(M=5.66, S D=1.08)$ : $F(1,288)=8.21, p=.004, \eta^{2}=.03$. This could also be observed between older $(M=6.10, S D=.92)$ and younger $(M=5.71, S D=1.01)$ scientific experts: $F(1,288)=11.72$, $p=.001, \eta^{2}=.04$. Contrary to assumptions drawn from past studies, there is not prove in the data regarding significant gender difference or any effects regarding integrity and benevolence.

While there are only a few small differences in perceived expertise, the chosen stimuli differ strongly regarding emotional assessment. Regarding the experts' ability to entertain (Table 4), all significant differences are between TV interviews and YouTube videos. When testing the effects of the stimulus dummy variables in additional analyses of variance, sciencetubers are significantly rated as more entertaining $(M=5.64, S D=1.27)$ than scientific experts interviewed on TV $(M=4.73, S D=1.48)$ : $F(1,288)=25.23, p<.001, \eta^{2}=.08$. Thus, $\mathrm{H} 1 \mathrm{a}$ is supported although the difference is smaller than one might expect. A similar, although, smaller effect appears when comparing older $(M=4.71, S D=1.56)$ and younger scientists $(M=5.32, S D=1.33): F(1,288)=12.40, p<.001$, $\eta^{2}=.04$. There is no significant difference in perceived entertaining abilities of male $(M=5.14, S D=1.48)$ compared to female scientific experts $(M=4.88, S D=1.47)$ : $F(1,294)=2.11, p=.15, \eta^{2}=.01$.

The two sciencetubers are also evaluated as being able to explain in the most comprehensible waystimulus 5 shows the highest and stimulus 2 the lowest mean comprehensibility (Table 4). Confirming $\mathrm{H} 1 \mathrm{~b}$, sciencetubers in sum $(M=6.34, S D=1.01)$ received significantly higher ratings than scientific experts interviewed on $\operatorname{TV}(M=5.30, S D=1.62): F(1,288)=31.31, p<.001$, $\eta^{2}=.10$. The effect by age revealed to be even higher with younger experts being evaluated as explaining more comprehensibly $(M=6.14, S D=1.15)$ than older experts $(M=5.11, S D=1.68): F(1,288)=36.90, p<.001$, $\eta^{2}=.11$. Additionally, according to the respondents' evaluation, female experts explain scientific information slightly more comprehensibly $(M=5.79, S D=1.39)$ than male experts $(M=5.44, S D=1.64): F(1,294)=9.03$, $p<.05, \eta^{2}=.01$.

Furthermore, whether a scientific expert is rated as being a typical scientist may be connected to the video format and the expert's age. The scientists who were evaluated as most typical (stimulus 1,3 ) were both middle-aged and are also the ones whose expertise was evaluated highest. The least typical scientists were the young sciencetubers (stimulus 5, 6, Table 4). Revealing in the biggest effect here and confirming $\mathrm{H} 1 \mathrm{c}$, sciencetubers were regarded as significantly less typical $(M=3.52$, $S D=1.69)$ than scientists appearing in TV interviews $(M=5.14, S D=1.40): F(1,288)=73.40, p<.001$, $\eta^{2}=.20$. As a logical consequence, younger experts are perceived as being less typical scientists $(M=3.90$, $S D=1.66)$ than older experts $(M=5.37, S D=1.33)$ : $F(1,288)=69.08, p<.001, \eta^{2}=.19$. By contrast, no significant gender difference was found between female $(M=4.56, S D=1.59)$ and male experts $(M=4.70$, $S D=1.74): F(1,294)=.50, p=.48, \eta^{2}=.002$.

In sum, while the different stimuli and therefore scientific experts in TV interviews and YouTube videos show only minor significant differences regarding expertise and none regarding integrity and benevolence, they strongly vary in the levels of emotional assessment.

\subsection{Predictors of Perceived Trustworthiness}

Our second aim of this study is to identify the predictors of perceived trustworthiness using a linear regression model with the focus on the role of the video format and emotional assessment (RQ2). The predictors explain an especially high amount of variance for expertise and greater variance for perceived integrity than benevolence (Table 5).

In contrast to our previous assumption, viewing a stimulus featuring a female STEM expert as opposed to a male expert has a small positive and significant effect on perceived expertise. Furthermore, as predicted, viewing an older as opposed to a younger expert also leads to a higher rating in perceived expertise. No other statistically significant effects were found for gender or age. Additionally, the video format itself does not significantly predict scientific experts' perceived trustworthiness.

The central assumption that trustworthiness is formed by emotional processes is confirmed by the model. The level of perceived entertaining abilities of 
Table 4. Mean differences in the evaluation of scientists per stimulus (ANOVA with post-hoc test).

\begin{tabular}{|c|c|c|c|c|c|c|c|c|c|c|}
\hline & $\begin{array}{l}\text { Total average } \\
\quad(n=302)\end{array}$ & $\begin{array}{l}\text { Stimulus } 1 \\
(n=52)\end{array}$ & $\begin{array}{l}\text { Stimulus } 2 \\
(n=52)\end{array}$ & $\begin{array}{l}\text { Stimulus } 3 \\
(n=46)\end{array}$ & $\begin{array}{c}\text { Stimulus } 4 \\
(n=56)\end{array}$ & $\begin{array}{l}\text { Stimulus } 5 \\
(n=50)\end{array}$ & $\begin{array}{c}\text { Stimulus } 6 \\
(n=46)\end{array}$ & $F(d f)$ & $\eta^{2}$ & $f$ \\
\hline Expert's gender & & $\mathrm{m}$ & $\mathrm{m}$ & $f$ & $f$ & $\mathrm{~m}$ & $f$ & & & \\
\hline Expert's age & & 50 & 80 & 61 & 36 & 34 & 31 & & & \\
\hline Video format & & TV & TV & TV & TV & YouTube & YouTube & & & \\
\hline \multicolumn{11}{|l|}{ Perceived trustworthiness } \\
\hline Expertise & $5.91(.98)$ & $6.15(.79)^{\mathrm{a}}$ & $5.86(1.08)$ & $6.33(.81)^{b}$ & $5.80(.88)$ & $5.49(1.14)^{\mathrm{a}, \mathrm{b}}$ & $5.88(.99)$ & $4.41 * * *(5,284)$ & .07 & .27 \\
\hline Integrity & $5.47(1.02)$ & $5.52(1.01)$ & $5.41(1.10)$ & $5.56(1.17)$ & $5.48(.84)$ & $5.52(1.01)$ & $5.30(1.05)$ & $.36(5,283)$ & .01 & .10 \\
\hline Benevolence & $5.10(1.09)$ & $5.20(1.01)$ & $5.00(1.18)$ & $5.18(1.24)$ & $5.23(.98)$ & $5.06(1.05)$ & $4.89(1.09)$ & $.67(5,281)$ & .01 & .10 \\
\hline \multicolumn{11}{|l|}{ Emotional assessment } \\
\hline Boring/entertaining & $5.01(1.48)$ & $5.30(1.34)$ & $4.44(1.63)^{a, b}$ & $4.38(1.54)^{c}$ & $4.78(1.27)^{d}$ & $5.71(1.15)^{\mathrm{a}, \mathrm{d}}$ & $5.55(1.41)^{b, c}$ & $7.96 * * *(5,284)$ & .12 & .37 \\
\hline Incomprehensible/comprehensible & $5.62(1.53)$ & $5.58(1.41)^{a, b}$ & $4.31(1.77)^{a, c, d, e, f}$ & $5.51(1.55)^{c, g}$ & $5.81(1.29)^{d}$ & $6.50(.68)^{b, e, g}$ & $6.13(1.28)^{f}$ & $14.93 * * *(5,284)$ & .21 & .52 \\
\hline Atypical/typical & $4.64(1.66)$ & $5.48(1.30)^{\mathrm{a}, \mathrm{b}}$ & $5.21(1.39)^{c, d}$ & $5.42(1.31)^{e, f}$ & $4.54(1.41)^{\mathrm{g}}$ & $3.35(1.69)^{a, c, e, g}$ & $3.73(1.68)^{b, d, f}$ & $18.27 * * *(5,284)$ & .24 & .56 \\
\hline
\end{tabular}

Notes: Ratings on a scale from 1 to 7 . Matching letters indicate significant mean differences (Scheffé Post-hoc test). 
Table 5. Linear regression predicting scientific experts' perceived trustworthiness.

\begin{tabular}{|c|c|c|c|c|c|c|}
\hline \multirow[t]{2}{*}{ Predictors } & \multicolumn{2}{|c|}{$\begin{array}{l}\text { Expertise } \\
(n=280)\end{array}$} & \multicolumn{2}{|c|}{$\begin{array}{l}\text { Integrity } \\
(n=279)\end{array}$} & \multicolumn{2}{|c|}{$\begin{array}{l}\text { Benevolence } \\
\quad(n=277)\end{array}$} \\
\hline & $\beta$ & $95 \% \mathrm{Cl}$ of $B$ & $\beta$ & $95 \% \mathrm{Cl}$ of $B$ & $\beta$ & $95 \% \mathrm{Cl}$ of $B$ \\
\hline Constant & & {$[-8.25,20.79]$} & & {$[-3.39,30.73]$} & & {$[-14.44,23.23]$} \\
\hline \multicolumn{7}{|l|}{ Stimuli } \\
\hline TV interview vs. YouTube video & -.01 & {$[-.28, .33]$} & -.02 & {$[-.41, .31]$} & -.09 & {$[-.61, .19]$} \\
\hline Scientist's gender (male vs. female) & $.19 * * *$ & {$[.15, .58]$} & .02 & {$[-.21, .29]$} & .02 & {$[-.24, .32]$} \\
\hline Scientist's age (old vs. young) & $-.24 * *$ & {$[-.78,-.17]$} & -.08 & {$[-.51, .20]$} & .01 & {$[-.37, .41]$} \\
\hline \multicolumn{7}{|l|}{ Emotional assessment } \\
\hline Boring/entertaining & $.34 * * *$ & {$[.15, .30]$} & $.25 * * *$ & {$[.08, .26]$} & $.20^{*}$ & {$[.04, .25]$} \\
\hline Incomprehensible/comprehensible & $.17^{* *}$ & {$[.03, .18]$} & $.19 * *$ & {$[.04, .21]$} & $.14^{*}$ & {$[.01, .20]$} \\
\hline Atypical/typical & $.33 * * *$ & {$[.13, .26]$} & $.16^{*}$ & {$[.02, .18]$} & $.19 * *$ & {$[.04, .21]$} \\
\hline \multicolumn{7}{|l|}{ Viewers' attributes } \\
\hline Trust in scientists & .10 & {$[-.01, .29]$} & .01 & {$[-.16, .19]$} & -.01 & {$[-.20, .19]$} \\
\hline Interest in science & .01 & {$[-.11, .14]$} & $.12^{*}$ & {$[.01, .29]$} & .02 & {$[-.13, .19]$} \\
\hline Science TV use & -.02 & {$[-.09, .06]$} & $-.12^{*}$ & {$[-.18,-.01]$} & -.06 & {$[-.15, .05]$} \\
\hline Science online video use & -.01 & {$[-.10, .08]$} & -.04 & {$[-.13, .08]$} & -.08 & {$[-.18, .05]$} \\
\hline Gender $(2=$ male $)$ & -.09 & {$[-.41, .03]$} & $-.20 * * *$ & {$[-.68,-.17]$} & -.08 & {$[-.45, .11]$} \\
\hline Age & .03 & {$[.01,-.01]$} & .07 & {$[.01,-.01]$} & -.01 & {$[.01,-.01]$} \\
\hline Education $^{1}$ & .04 & {$[-.08, .16]$} & -.10 & {$[-.27, .02]$} & $-.22 * * *$ & {$[-.45 .-.14]$} \\
\hline$F$ total $(d f)$ & \multicolumn{2}{|c|}{$14.73^{* * *}(13,267)$} & \multicolumn{2}{|c|}{$7.34 * * *(13,266)$} & \multicolumn{2}{|c|}{$5.09 * * *(13,264)$} \\
\hline Total $R^{2}$ & & .39 & & .23 & & .16 \\
\hline
\end{tabular}

Notes: Standardised $\beta$-values are reported, ${ }^{*} p \leq .05,{ }^{* *} p \leq .01,{ }^{* * *} p \leq .001 .{ }^{1}$ No school degree $=1$, Graduation from Secondary Education (Hauptschule) $=2$, Graduation from Secondary Education (Realschule) $=3$, Higher Secondary Education $=4$, University Degree $=5$, Doctoral Degree $=6$.

scientific experts was shown to be the strongest positive predictor for expertise and one of the strongest for integrity as well as benevolence. As predicted in $\mathrm{H} 2 \mathrm{a}$ and $\mathrm{H} 2 \mathrm{~b}$, ratings of communicating scientific information comprehensibly and of being perceived as a typical scientist have positive effects on all dimensions of perceived trustworthiness. Despite theoretical suggestions that general trust in scientists is closely connected to perceived trustworthiness of specific experts, the small effect on expertise is not significant in our regression model. Therefore, and interestingly, the connection between the two concepts is not as strong as expected by $\mathrm{H} 3$. When comparing the correlations for the different video formats, we find small significant effects for videos in the TV interview setting (expertise: $r=.19, p \leq .01$; integrity: $r=.12, p \leq .05$; benevolence: $r=.11, p>.05)$ and no effect for YouTube videos (expertise: $r=.04, p>.05$; integrity: $r=.04, p>.05$; benevolence: $r=-.07, p>.05$ ).

Lastly, the regression analyses show that some of the viewers' attributes, as well as socio-demographics, significantly predict the perceived trustworthiness of scientists: Contrary to previous research on general trust in science, female respondents perceive scientists' integrity significantly higher than male respondents. Also contrary to previous research on general trust in science, respondents with lower levels of educational attainment are more convinced that scientists act morally and responsibly. The higher people's educational attainments are, the less idealised or more critical their impression of scientific experts is. The analysis revealed no age effect. Additionally, interest in science only has a positive effect on whether scientific experts are perceived as honest and fair (integrity). A higher frequency of science TV use has the opposite effect.

\subsection{Mediation Effects of Emotional Assessment}

According to this study's third aim and research question, we want to explore whether emotional assessment variables are mediators of the stimulus effects (TV interview vs. YouTube video) on perceived trustworthiness. Thus, we want to shed light on the process of evaluating scientific experts' trustworthiness. We used Hayes' PROCESS macro (version 3.0, model 4) in SPSS with 10.000 bootstrap samples and added viewers' gender, age, and educational attainment as covariates. The covariates in the models revealed the same significant effects in perceived trustworthiness as in the linear regression analyses. Additionally, age has a tiny but significant positive effect on all emotional assessment variables.

The three models (Figure 2 ) revealed that sciencetubers were rated as significantly more entertaining 

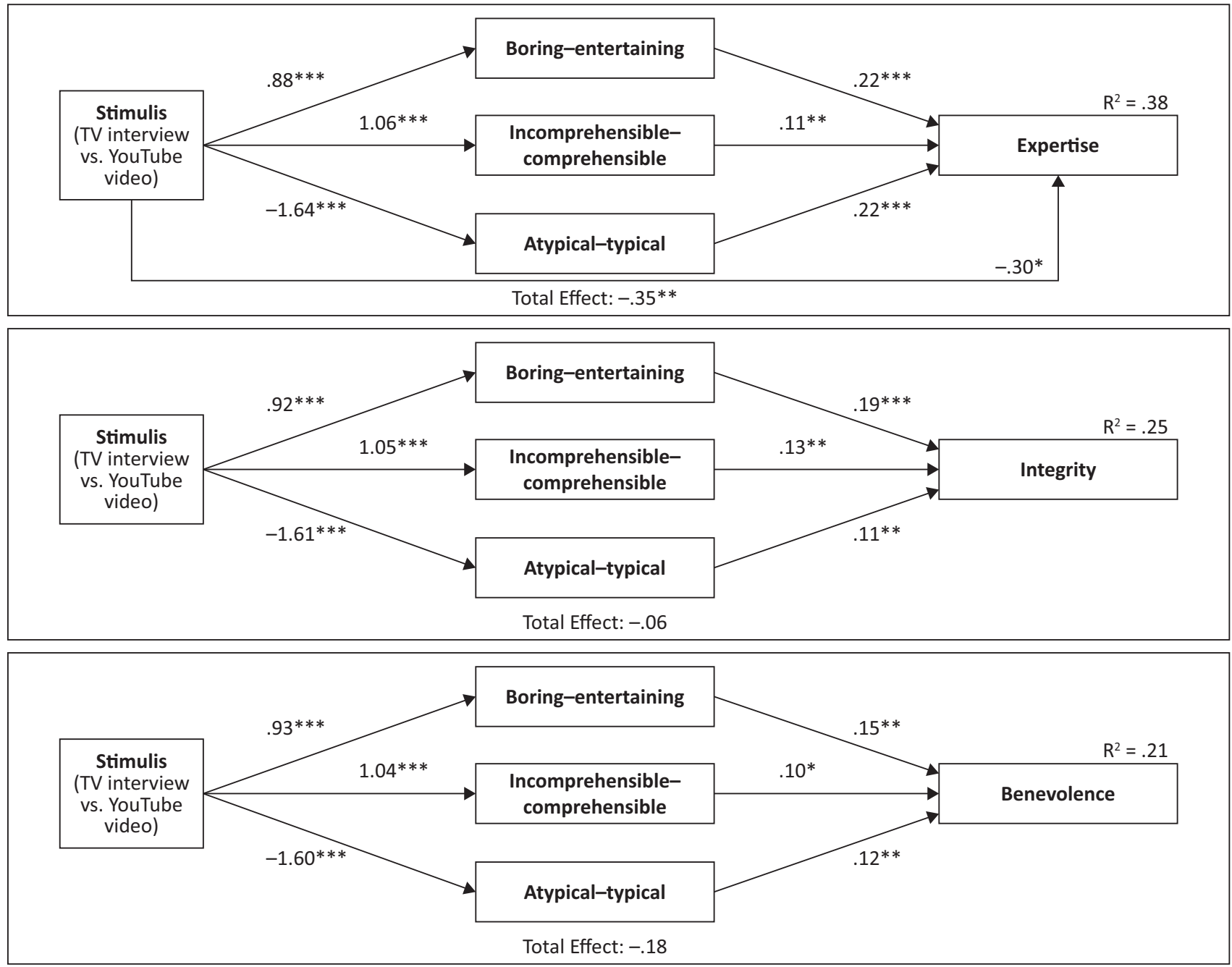

Figure 2. Mediation models for direct and indirect effects of stimulus on perceived trustworthiness. Notes: Unstandardised coefficients are reported, $* p \leq .05, * * p \leq .01, * * * p \leq .001$.

$(t(280)=4.88, p<.001)$ and more comprehensible $(t(280)=5.58, p<.001)$ than scientific experts appearing in TV interviews. They were regarded as being less typical scientists than scientists featured in TV interviews $(t(280)=-9.50, p<.001)$.

We discovered significant negative direct effects by the stimulus variable on expertise $(t(277)=-2.41$, $p<.05)$. The negative direct effect on integrity $(t(276)=$ $-1.29, p=.20)$ and benevolence $(t(277)=-1.55, p=.12)$ are not significant.

Focusing on affective assessment and thereby on scientific experts' entertaining abilities, we found-similar to the single linear regression models in Section 5.2significant positive effects on expertise $(t(277)=5.66$, $p<.001)$, integrity $(t(276)=4.18, p<.001)$, and benevolence $(t(274)=3.07, p<.01)$. The bootstrapped estimates of the indirect effects were small but significant for all three dimensions of perceived trustworthiness (expertise: $\beta=.20, \mathrm{SE}=.05,95 \% \mathrm{Cl}[.10, .30]$; integrity: $\beta=.17$, $\mathrm{SE}=.06,95 \% \mathrm{Cl}[.07, .29]$; benevolence: $\beta=.13, \mathrm{SE}=.06$, $95 \% \mathrm{Cl}[.03, .25])$.

Furthermore, the more comprehensible an expert is perceived as, the higher the rating of their exper- tise $(t(277)=3.04, p<.01)$, integrity $(t(276)=2.99$, $p<.01)$, and benevolence $(t(274)=2.23, p<.05)$. Similar to the mediation effects of perceived entertaining abilities, all indirect effects of the stimulus variable on perceived trustworthiness through comprehensibility were small but significant (expertise: $\beta=.12, \mathrm{SE}=.05,95 \% \mathrm{Cl}$ $[.04, .22]$; integrity: $\beta=.13, \mathrm{SE}=.05,95 \% \mathrm{Cl}[.04, .23]$; benevolence: $\beta=.10, \mathrm{SE}=.05,95 \% \mathrm{Cl}[.01, .20])$. The second variable measuring cognitive assessment indicates, as expected, a different effect. While being assessed as a more typical scientist positively affects expertise $(t(276)=7.02, p<.001)$, integrity $(t(276)=3.10, p<.01)$, and benevolence $(t(274)=2.91, p<.01)$, the negative indirect effect by the stimulus variable on all dimensions of perceived trustworthiness are significant. The indirect effect of the stimulus on expertise is mediocre and thereby the strongest indirect effect $(\beta=-.37, \mathrm{SE}=.07,95 \% \mathrm{Cl}$ $[-.52,-.24])$. The indirect effects on integrity $(\beta=-.18$, $\mathrm{SE}=.06,95 \% \mathrm{Cl}[-.31,-.06])$, and benevolence $(\beta=-.17$, $\mathrm{SE}=.07,95 \% \mathrm{Cl}[-.29,-.06])$ are small.

These results suggest that viewers emotionally assess scientific experts who appear in video content in order to evaluate their trustworthiness. As a result of the 
rather strong negative indirect effect caused by the assumption that sciencetubers are regarded as being atypical scientists and the weaker positive indirect effects caused by their entertaining abilities and comprehensibility, the total indirect effects are not significant (expertise: $\beta=-.06, \mathrm{SE}=.01,95 \% \mathrm{Cl}[-.26, .15]$; integrity: $\beta=-.12, \mathrm{SE}=.01,95 \% \mathrm{Cl}[-.07, .32]$; benevolence: $\beta=.06, \mathrm{SE}=.01,95 \% \mathrm{Cl}[-.13, .23])$. However, in terms of total effects, only the negative effect by the sciencetuber stimuli on expertise remains significant $(t(280)=-2.81$, $p<.01)$.

\section{Limitations}

The selection of stimuli must be critically addressed. Even though the real stimulus material was chosen to minimise variance, each stimulus differs. Our self-imposed restriction on having to have German-language physics videos of high production quality led to there being a very small number of eligible videos. As a result, we were only able to use two YouTube videos as opposed to four TV interviews, leading to a smaller sample size for the former. Similar restrictions applied to the TV interviews since we wanted them all to be from the same interview series in order to have a more comparable sample. However, the second stimulus video was somewhat outdated and had a lower image quality.

Further, not only did the video format vary but also the scientific experts between stimuli. While the scientific experts interviewed on TV were noticeably not trained in science communication, the sciencetubers were professional science communicators. Therefore, the sciencetubers could be considered more comparable to journalists or presenters on TV, and the results may indicate that the respondents did not perceive them as being real scientists. Three respondents who evaluated the expert in stimulus 5 and one respondent for stimulus 6 stated this perception in their answers to an additional open-ended question. There were no such comments regarding the experts who appeared in the TV interview setting. Although all stimuli were in the field of physics, the specific topics addressed varied slightly. We tried to consider scientific experts who varied in age and gender but finding sciencetubers of different ages was difficult. Thus, the age, besides different factors, may also have impacted the stimulus effects. The female physicists chosen as stimuli are on average younger than the male ones, but this is in part a reflection of the scientists featured in the interview series we drew from. Apart from that, two experts differed significantly from the others. The oldest expert in stimulus 2 stood out for the lowest means on diverse items. The expert in stimulus 6 is a rather wellknown sciencetuber who now hosts a science show on German TV and is also the only expert shown who is not of European ethnicity.

Another limitation of this study is that the sample is highly educated, rather interested in science, and young which is why it cannot be assumed as representative for
Germany. Especially the young age of respondents and higher contact with online science videos may have influenced more positive ratings of perceived trustworthiness for the sciencetubers.

Finally, the decision to use the three-fold construct of perceived trustworthiness has to be critically addressed. We used the METI scale as it was invented to measure perceived trustworthiness in scientific experts in online contexts which is practically the most specific instrument for our study. Gheorghiu (2017) also gives evidence towards a better model fit for measuring three dimensions over two in confirmatory factor analyses. However, more research is needed to compare different measures. Especially because we found hints towards two factors in an exploratory factor analysis.

\section{Conclusion}

The goal of this study was to extend trust and trustworthiness research in the field of science communication to consider the emotional assessments of scientific experts in emerging online video content.

An experimental online survey $(n=155)$ using six different video stimuli was conducted to explore the predictors of perceived trustworthiness and more specifically the role of video format and emotional assessment of scientific experts.

Firstly, the sciencetubers in this study were perceived as less competent but just as honest and benevolent as scientific experts who appeared in TV interviews. While the scientists interviewed on TV were regarded as typical scientists, sciencetubers stand out for their highly professional communication abilities. Content presented by scientific experts on YouTube videos was regarded as highly comprehensible and entertaining. As discussed in the limitations, these results may also be influenced by the fact that the studied sciencetubers are professional science communicators and may not have been perceived as scientists. Strictly controlling for this in the selection of stimulus material in future experimental research can diminish most of the limitations. Furthermore, viewers' expectations were not researched here, but they are important at the science-public-interface and in the mutual understanding of experts and laypeople (Bromme \& Jucks, 2017). What the non-expert audience expects from the experts' communication thus affects how this is perceived (Taddicken \& Wicke, 2019). This might have affected the perceptions of the sciencetubers. Expectations regarding the format of explainer videos on YouTube in contrast to TV interviews should be considered in future research.

Secondly, our results highlight the emotional assessment (entertaining, comprehensible, and typical) of scientific experts and thereby a first impression as an important predictor of perceived trustworthiness. Scientists' attributes connected to stereotypes about scientists, such as their gender and age only affect expertise-for gender, however, we found the opposite effect similar to 
the findings of Jarreau et al. (2019). Female respondents also evaluated the scientific experts as having more integrity than male respondents and higher educational attainment was found to lead to lower perceived benevolence. General trust in scientists and specific trustworthiness were not significantly linked in our model. While we only found small significant correlations between the variables for scientific experts appearing in TV interviews, there were no correlations for sciencetuberswho may not have been perceived as being scientists. However, more research is needed to examine the relationship between trust and trustworthiness. While general trust in science is assumed to be a procedural variable but relatively stable over time, trustworthiness for specific experts is highly situational. Transfer effects between trust and trustworthiness seem to be more complex than linear, and mutually affecting. Trust in scientists as general beliefs may be more strongly affected by stereotypical views (e.g., ambivalent stereotype of scientists), whereas perceptions of specific individuals may be less stereotypical. In turn, repeated contact with 'real' scientists may help to diminish existing stereotypes. Longitudinal research is needed to explore the dynamics in greater detail.

Finally, by mediation analyses, we have detected that emotional assessment mediates the effects of the stimulus (TV vs. YouTube) on perceived trustworthiness. When audiences are exposed to scientific experts in videos, they emotionally assess them which helps them to evaluate their trustworthiness.

This study serves as a starting point for further discussion. It highlights the importance of considering emotions when studying trustworthiness. If audiences feel more entertained by, and/or understand scientific experts' explanations, this can have a positive effect on perceived trustworthiness. New online formats and young sciencetubers have to be acknowledged as a crucial part of current science communication to the public. They should be considered significantly more often in the academic discussion about how to build or retain trust in scientists and science in general.

Further, strictly controlled experiments are required to dig deeper into the numerous relationships and effects and to explore the processes of emotional assessment and how these affect the audiences' trustworthiness perception in greater detail. Future research should also consider including emotions that may appear at the different stages in the process of evaluating trustworthiness, such as: (a) the emotions expressed by scientists; and (b) the emotions evoked by the audiences.

\section{Acknowledgments}

We thank all respondents and our students who recruited members for our pool of study participants. Furthermore, we thank the two anonymous reviewers for their constructive feedback on a previous version of the article. We acknowledge support by the Braunschweiger
Netzwerk für Gender und Diversity Studies, the German Research Foundation and the Open Access Publication Funds of the Technische Universität Braunschweig.

\section{Conflict of Interests}

The authors declare no conflicts of interest.

\section{References}

Aljazzaf, Z. M., Perry, M., \& Capretz, M. A. M. (2010). Online trust: Definition and principles. In M. Garcia \& J.-D Mathias (Eds.), 2010 Fifth international multiconference on computing in the global information technology (pp. 163-168). Piscataway, NJ: Institute of Electrical and Electronics Engineers. https://doi. org/10.1109/ICCGI.2010.17

Amarasekara, I., \& Grant, W. J. (2019). Exploring the YouTube science communication gender gap: A sentiment analysis. Public Understanding of Science, 28(1), 68-84. https://doi.org/10.1177/0963662518786654

Bromme, R., \& Jucks, R. (2017). Discourse and expertise: The challenge of mutual understanding between experts and laypeople. In M. F. Schober, D. N. Rapp, \& M. A. Britt (Eds.), The Routledge handbook of discourse processes (pp. 222-246). Abingdon: Routledge.

Buldu, M. (2006). Young children's perceptions of scientists: A preliminary study. Educational Research, 48(1), 121-132. https://doi.org/10.1080/ 00131880500498602

Carli, L. L., Alawa, L., Lee, Y., Zhao, B., \& Kim, E. (2016). Stereotypes about gender and science. Psychology of Women Quarterly, 40(2), 244-260. https://doi.org/ $10.1177 / 0361684315622645$

Dernbach, B., \& Meyer, M. (2005). Vertrauen und Glaubwürdigkeit: Interdisziplinäre Perspektiven [Trust and credibility: Interdisciplinary perspectives] (1st ed.). Wiesbaden: Springer VS.

Earle, T. C., \& Siegrist, M. (2006). Morality information, performance information, and the distinction between trust and confidence. Journal of Applied Social Psychology, 36(2), 383-416. https://doi.org/ 10.1111/j.0021-9029.2006.00012.x

European Commission. (2013). Special eurobarometer 401: Responsible research and innovation (RRI), science and technology. Luxembourg: European Union. Retrieved from http://data.europa.eu/88u/dataset/ S1096_79_2_401

Finson, K. D. (2002). Drawing a scientist: What we do and do not know after fifty years of drawings. School Science and Mathematics, 102(7), 335-345. https:// doi.org/10.1111/j.1949--8594.2002.tb18217.x

Fiske, S. T., Cuddy, A. J. C., Glick, P., \& Xu, J. (2002). A model of stereotype content as often mixed: Separate dimensions of competence and warmth respectively follow from status and competition. Journal of Personality and Social Psychology, 82(6), 171-222.

Fiske, S. T., \& Dupree, C. (2014). Gaining trust as well 
as respect in communicating to motivated audiences about science topics. Proceedings of the National Academy of Sciences of the United States of America, 111(Suppl. 4), 13593-13597. https://doi.org/ $10.1073 /$ pnas. 1317505111

Friesen, J., van Stan, J., \& Elleuche, S. (2018). Communicating science through comics: A method. Publications, 6(3), 38. https://doi.org/10.3390/ publications6030038

Gerber, A. (2012). Trendstudie Wissenschaftskommunikation. Vorhang auf für Phase 5: Chancen, Risiken und Forderungen für die nächste Entwicklungsstufe der Wissenschaftskommunikation [Science communication trend study. Raise the curtain for the 5th stage: Chances, risks, and demands for the next stage of developments in science communication] (Vol. 1). Berlin: Edition innovare/innokomm Forschungszentrum.

Gheorghiu, A. I. (2017). The face of research: Do first impressions based on the facial appearance of scientists affect the selection and evaluation of science communication? (Unpublished Doctoral dissertation). University of Essex, Colchester, UK.

Giddens, A. (1991). The consequences of modernity. Cambridge: Polity Press.

Gigante, M. E. (2018). Introducing science through images. Columbia, SC: University of South Carolina Press. https://doi.org/10.2307/j.ctv6sj8kf

Grünberg, P. (2014). Vertrauen in das Gesundheitssystem: Wie unterschiedliche Erfahrungen unsere Erwartungen prägen [Trust in the health care system: How different experiences shape our expectations]. Wiesbaden: Springer VS. https://doi.org/ 10.1007/978-3-658-04350-6_6

Hasell, A., Tallapragada, M., \& Brossard, D. (2019). Deference to scientific authority, trust and credibility: Distinguishing three connected constructs in science communication. Paper presented at the Annual Conference of the International Communication Association, Washington, D.C., USA.

Hendriks, F., Kienhues, D., \& Bromme, R. (2015). Measuring laypeople's trust in experts in a digital age: The Muenster epistemic trustworthiness inventory (METI). PloS One, 10(10), e0139309. https://doi.org/ 10.1371/journal.pone.0139309

Hovland, C. I., Janis, I. L., \& Kelley, H. H. (1953). Communication and persuasion. New Haven, CT: Yale University Press.

Huber, B., Barnidge, M., Gil de Zúñiga, H., \& Liu, J. (2019). Fostering public trust in science: The role of social media. Public Understanding of Science, 28(7), 759-777. https://doi.org/10.1177/0963662519869097

Janecek, S. (2008). Filming Science: Wie funktioniert Wissenschaft im Fernsehen? [Filming science: How does science work on TV?]. Saarbrücken: VDM Verl. Müller.

Jarreau, P. B., Cancellare, I. A., Carmichael, B. J., Porter, L., Toker, D., \& Yammine, S. Z. (2019). Using self- ies to challenge public stereotypes of scientists. PloS One, 14(5), e0216625. https://doi.org/10.1371/ journal.pone.0216625

Kaczinski, A., Hennig-Thurau, T., \& Sattler, H. (2019). Social Media \& Society Report: Wie Deutschland soziale Medien nutzt und was das für unsere Gesellschaft bedeutet [Social media \& society report: How Germany uses social media and what this means for our society]. Hamburg: DFG-Forschergruppe 1452 "How Social Media Is Changing Marketing". Retrieved from https://www.marketingcenter.de/sites/mcm/ files/downloads/research/lmm/literature/kaczinski_ hennig-thurau_sattler_social_media_and_society_ report_2019.pdf

Kitzinger, J., Chimba, M. D., Williams, A., Haran, J., \& Boyce, T. (2016). Gender, stereotypes and expertise in the press: How newspapers represent female and male scientists (Project report). Bradford and Cardiff: UK Resource Centre for Women in Science, Engineering and Technology and Cardiff University. Retrieved from http://orca.cf.ac.uk/id/eprint/28633

Lakomý, M., Hlavová, R., \& Machackova, H. (2019). Open science and the science-society relationship. Society, 56(3), 246-255. https://doi.org/10.1007/ s12115--019-00361-w

Mayer, R. C., Davis, J. H., \& Schoorman, F. D. (1995). An integrative model of organizational trust. Academy of Management Review, 20(3), 709-734. https://doi. org/10.5465/AMR.1995.9508080335

McCroskey, J. C., \& Teven, J. J. (2009). Goodwill: A reexamination of the construct and its measurement. Communication Monographs, 66(1), 90-103. https:// doi.org/10.1080/03637759909376464

Prommer, E., \& Linke, C. (2017). Audiovisuelle Diversität? Geschlechterdarstellungen in Film und Fernsehen in Deutschland [Audiovisual diversity? Gender portrayal in films and on television in Germany]. Rostock: Universität Rostock. Retrieved from https://www. uni-rostock.de/storages/uni-rostock/UniHome/ Presse/Pressemeldungen/Broschuere_din_a4_ audiovisuelle_Diversitaet_v06072017_V3.pdf

Rabah, J., Cassidy, R., \& Beauchemin, R. (2018). Gamification in education: Real benefits or edutainment? Paper presented at the 17th European Conference on e-Learning, Athens, Greece.

Reif, A. (in press). Mehr Raum für Vertrauen? Potenzielle Veränderungen des Vertrauens in Wissenschaft durch partizipative Onlineumgebungen [More space for trust? Potential changes of trust in science through participatory online environments]. In T. Döbler, C. Pentzold, \& C. Katzenbach (Eds.), Räume digitaler Kommunikation [Spaces of digital communication]. Köln: Herbert von Halem.

Röben, B. (2013). Medienethik und die "Anderen": Multiperspektivität als neue Schlüsselkompetenz [Media ethics and the "others": Multi-perspectivity as new key skill]. Wiesbaden: Springer VS. Retrieved from https://www.springer.com/de/book/ 


\section{5}

Schweiger, W. (2013). Handbuch Medienwirkungsforschung [Handbook of media effects research]. Wiesbaden: Springer VS.

Simpson, J. A. (2007). Psychological foundations of trust. Current Directions in Psychological Science, 16(5), 264-268. https://doi.org/10.1111/j.1467-8721.2007.00517.x

Spohr, D. (2017). Fake news and ideological polarization. Business Information Review, 34(3), 150-160. https://doi.org/10.1177/0266382117722446

Sugimoto, C. R., Thelwall, M., Larivière, V., Tsou, A., Mongeon, P., \& Macaluso, B. (2013). Scientists popularizing science: Characteristics and impact of TED talk presenters. PloS One, 8(4), e62403. https://doi.org/ 10.1371/journal.pone.0062403

Taddicken, M., \& Reif, A. (2016). Who participates in the climate change online discourse? A typology of Germans' online engagement. Communications, 41(3), 315-337. https://doi.org/10.1515/commun2016--0012

Taddicken, M., \& Wicke, N. (2019). Erwartungen an und Bewertungen der medialen Berichterstattung über den Klimawandel aus Rezipierendenperspektive [Expectations and evaluation of the climate change media coverage from the recipients' per- spective]. In I. Neverla, M. Taddicken, I. Lörcher, \& I. Hoppe (Eds.), Klimawandel im Kopf: Studien zur Wirkung, Aneignung und Online-Kommunikation [Climate change in the head: Studies about effects, acquisition, and online communication] (pp. 145-172). Wiesbaden: Springer. https://doi.org/10.1007/978-3-658--22145-4_6

Türkmen, H. (2008). Turkish primary students' perceptions about scientist and what factors affecting the image of the scientists. Eurasia Journal of Mathematics, Science and Technology Education, 4(1), 55-61. https://doi.org/10.12973/ejmste/75306

von Roten, F. C. (2016). Gender differences in attitudes toward science in Switzerland. Public Understanding of Science, 13(2), 191-199. https://doi.org/10.1177/ 0963662504043870

Welbourne, D. J., \& Grant, W. J. (2016). Science communication on YouTube: Factors that affect channel and video popularity. Public Understanding of Science, 25(6), 706-718. https://doi.org/10.1177/ 0963662515572068

Wissenschaft im Dialog. (2018). Wissenschaftsbarometer 2018 [Science barometer 2018]. Wissenschaft im Dialog. Retrieved from https://www.wissenschaftim-dialog.de/projekte/wissenschaftsbarometer/ wissenschaftsbarometer-2018

\section{About the Authors}

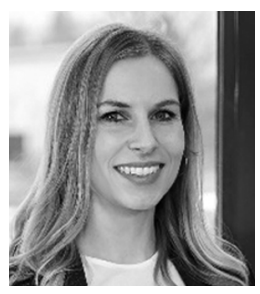

Anne Reif is a Research Assistant at the Department of Communication and Media Sciences at the Technische Universität Braunschweig, Germany. She holds an M.A. degree in Media and Communication Science from the Ilmenau University of Technology, Germany. She is currently working on her PhD project about trust in science and the use of online media from the audience's perspective. Her further research interests are in the field of gender studies.

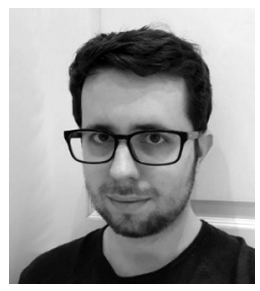

Tim Kneisel is a Master's Student in Media Technology and Communication at the Technische Universität Braunschweig. Aside from science communication, his studies focus on different forms of digital communication and human-computer interaction. He is currently working on his Master's thesis on the topic of neural-network-based audio-visual speech recognition.

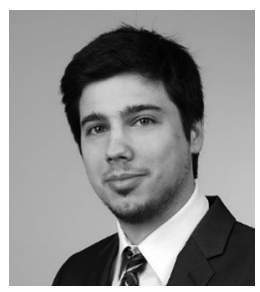

Markus Schäfer is a Master's Student in Media Technology and Communication at the Technische Universität Braunschweig. Aside from science communication, his studies focus on different forms of digital communication and human-computer interaction. He is currently working on his Master's thesis on the topic of concept development for the localization of base stations.

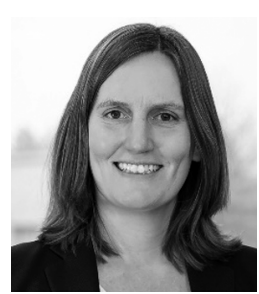

Monika Taddicken is a Professor of Communication and Media Sciences at the Technische Universität Braunschweig, Germany. She received her PhD in communication research from the University of Hohenheim, Germany, and is currently working on the audience's perspective of science communication. She has also published several articles on computer-mediated communication and social media, as well as on survey methodology. 